Vol. 8 No. 1 Maret 2020, Hal. 256-264

\title{
Penerapan Etika Pengambilan Keputusan Publik dalam Kebijakan Penertiban Kawasan Kalijodo
}

\author{
David Malchiel Ravanelli ${ }^{1)}$, Doni Ramadhan ${ }^{2)}$, Diva Agristya ${ }^{3)}$ Farrell Mochammad ${ }^{4)}$ \\ ${ }^{1)}$ Departemen Ilmu Administrasi Negara, Fakultas Ilmu Administrasi, Universitas Indonesia \\ E-mail: david.malchiel@ui.ac.id \\ ${ }^{2)}$ Departemen Ilmu Administrasi Negara, Fakultas Ilmu Administrasi, Universitas Indonesia \\ E-mail: doni.ramadhan@ui.ac.id \\ ${ }^{3)}$ Departemen Ilmu Administrasi Negara, Fakultas Ilmu Administrasi, Universitas Indonesia \\ E-mail: diva.agristya@ui.ac.id \\ ${ }^{4 \backslash}$ Departemen Ilmu Administrasi Negara, Fakultas Ilmu Administrasi, Universitas Indonesia \\ E-mail: farrell.mochammad@ui.ac.id
}

\begin{tabular}{l} 
INFO ARTIKEL \\
\hline Riwayat Artikel: \\
Diterima: 10-04-2020 \\
Disetujui: 27-04-2020 \\
\\
Kata Kunci: \\
1. $\quad$ Etika Pengambilan \\
keputusan Publik \\
2. Kebijakan publik \\
3. Penggusuran
\end{tabular}

Keyword:

1. Etichal decision making

2. Public policy

3. Eviction

\begin{abstract}
ABSTRAK
DKI Jakarta adalah ibukota negara Indonesia yang adalah pusat pemerintahan dan pusat perekonomian. Dengan demikian, hal tersebut berdampak pada pertumbuhan penduduk di Jakarta yang meningkat dengan pesat. Karena itu, keberadaan lahan sangat dibutuhkan dalam memenuhi kebutuhan penduduk Jakarta. Hal ini perlu diikuti dengan manajemen perencanaan tata ruang wilayah kota untuk menciptakan lingkungan yang nyaman, aman, dan berkelanjutan. Dalam usaha untuk menciptakan ruang terbuka hijau (RTH) sebsar $30 \%$ seperti yang telah ditetapkan dalam UU. No 26 Tahun 2007 tentang Penataan Ruang. Pemerintah Provinsi DKI Jakarta mengeluarkan kebijakan publik terhadap daerah yang seharusnya menjadi jalur hijau. Salah satu daerah yang sukses dikembalikan peruntukannya adalah kawasan Kalijodo, Jakarta Utara. Penggusuran oleh Pemerintah Provinsi DKI Jakarta adalah untuk mengembalikan fungsi ruang terbuka hijau di daerah tersebut. Dampaknya, penggusuran ini menyebabkan berbagai reaksi dari berbagai aktor kepentingan yang ada. Dalam menentukan kebijakan yang terbaik dalam menyelesaikan kasus ini diperlukan etika pengambilan keputusan publik. Terdapat tiga aspek meliputi konsekuensialis, deontologis, dan etika kebajikan. Tujuan dari penelitian ini adalah untuk menganalisis implementasi dari etika pengambilan keputusan publik dalam kebijakan penertiban kawasan Kalijodo tahun 2016. Penelitian ini menggunakan pendekatan deskriptif kualitatif.
\end{abstract}

\begin{tabular}{l} 
Abstract \\
DKI Jakarta Province is the capital city of Indonesia, in which also \\
is the center of government and national economy. Thus, this naturally \\
causes the population growth rate in Jakarta to increase rapidly. Therefore, \\
land is much needed to meet the needs of the people of Jakarta. This must \\
also be followed by the management of urban spatial planning in order to \\
create comfortable, safe and sustainable urban spaces. In an effort to create \\
a Green Open Space (RTH) of 30\% as written in UU No 26 Tahun 2007 \\
about Spatial Planning. The Provincial Government of DKI Jakarta impose \\
\hline
\end{tabular}


a public policy for areas that should be green lines. One of the regions that has been successfully carried out by the DKI Jakarta Provincial Government is the Kalijodo area located in North Jakarta. The eviction carried out by the DKI Jakarta Provincial Government aims to restore Kalijodo's function as a Green Open Space. In result, this eviction caused various reactions either from Kalijodo residents or the stakeholders. To decide which policy is the best used to overcome this issue the understanding of the ethical decision-making theory is needed. The aspects of said theory includes consecuentialist, deantological, and virtue ethics. The purpose of this research is to analyze the implementation of ethical decision-making theory of curbing policy in Kalijodo area in 2016. This study categorized as quantitative descriptive.

\section{LATAR BELAKANG}

Provinsi DKI Jakarta merupakan ibukota negara Indonesia yang menjadi pusat dari kegiatan pemerintahan dan perekonomian. Hal ini menyebabkan terjadinya peningkatan pertumbuhan penduduk setiap tahunnya, dengan jumlah penduduk pada tahun 2017 yaitu sebanyak 10.177.924 orang (BPS Provinsi DKI Jakarta, 2017). Berikut adalah grafik peningkatan jumlah penduduk DKI Jakarta dari tahun 1961-2017:

Gambar 1.1 Jumlah Penduduk DKI Jakarta

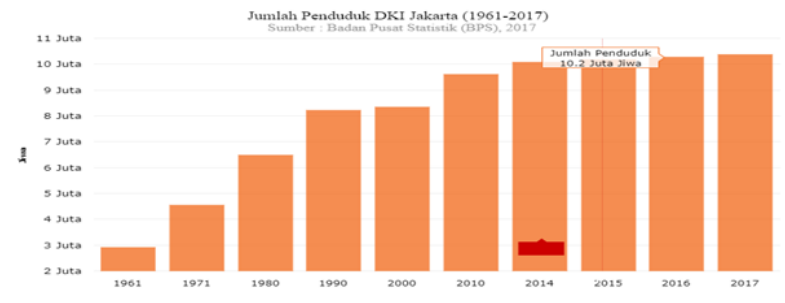

(Sumber: BPS, 2017)

Pesatnya pertumbuhan penduduk dan pembangunan fisik di Provinsi DKI Jakarta tidak diimbangi dengan jumlah ruang terbuka hijau yang ada. Kurangnya perhatian Pemda terhadap ketersediaan ruang terbuka hijau terlihat dari ruang terbuka hijau yang beralih fungsi menjadi bangunan-bangunan lain. Minimnya kesadaran dari masyarakat untuk menjaga dan melestarikan keberadaan ruang terbuka hijau di kota Jakarta juga merupakan salah satu faktor penyebab tidak tercapainya target pembangunan ruang terbuka hijau di Jakarta. Pada akhirnya timbul permasalahan seperti kemacetan, polusi udara, dan bencana banjir (Wijaya, 2013).
Pemerintah Provinsi DKI Jakarta telah berupaya untuk mewujudkan pembangunan ruang terbuka hijau (RTH) agar dapat mencapai standar yang telah ditetapkan oleh undang-undang yaitu sebesar 30 persen dari luas DKI Jakarta yang terhitung 7.659,02 $\mathrm{km}^{2}$. Upaya-upaya yang telah dilakukan oleh Pemerintah Provinsi DKI Jakarta sebagai contoh dengan perencanaan membangun 53 RTH dalam bentuk Taman Maju Bersama yang dapat dimanfaatkan sebagai ruang umum yang dapat digunakan untuk kegiatan publik. Upaya tersebut diwujudkan dengan melakukan penggusuran di lahan-lahan Jakarta yang terdapat banyak bangunan liar yang tidak memiliki izin untuk berdiri. Pada masa jabatan Gubernur Basuki Tjahaja Purnama atau yang biasa dipanggil Ahok, dalam dua tahun beliau tercatat sudah melakukan penggusuran sebanyak 12 kali. Salah satu contoh kasusnya adalah daerah Jakarta Timur yang meliputi Kampung Pulo dan Bidaracina di mana dilakukan penggusuran untuk program normalisasi Sungai Ciliwung agar banjir kiriman dari Bogor tidak meluap ke pemukiman warga. Contoh lainnya seperti di Bukit Duri, Pinangsia, Kemayoran, Waduk Pluit, Menteng Dalam, Kali Krukut, Pasar Ikan, dan yang terakhir adalah Kalijodo. Penertiban dilaksanakan dengan menggusur bangunanbangunan yang tidak memiliki izin agar lahan milik negara dapat dialihkan menjadi fungsi tujuannya, yaitu ruang terbuka hijau (RTH). Seringkali bangunan-bangunan liar tersebut disalahgunakan untuk kegiatan-kegiatan yang menyimpang dari norma sosial. Seperti di kawasan Kalijodo sendiri 
yang terkenal dengan aktivitas prostitusi, perjudian, perdagangan miras, dan premanisme. Penertiban terhadap kawasan Kalijodo dimulai pada awal tahun 2016 (Tambun, 2016). Kalijodo ini berada di Kelurahan Pejagalan, Kecamatan Penjaringan, Jakarta Utara. Kawasan tersebut telah ditertibkan pada awal tahun 2016 pada masa pemerintahan Gubernur Ahok. Daerah Kalijodo sendiri memiliki sejarah yang panjang dan kerap menjadi suatu daerah yang tabu untuk dibicarakan. Hal tersebut terjadi karena Kalijodo merupakan ladang perjudian dan pekerja seks komersil (Rizal, 2016).

Keputusan untuk melakukan penertiban terhadap kawasan Kalijodo tentu saja menuai pro dan kontra. Pihak yang menyatakan sikap kontra sebagian besar terdiri dari masyarakat yang mata pencahariannya berasal dari aktivitas di Kalijodo. Masyarakat tersebut memikirkan nasib keberlangsungan pekerjaan mereka yang apabila dilakukan penertiban akan hilang. Begitu pula warga yang sudah bertahun-tahun tinggal di kawasan Kalijodo yang khawatir mengenai tempat tinggal. Gubernur Basuki Tjahaja Purnama telah menawarkan solusi untuk permasalahanpermasalahan tersebut, bagi warga yang berdagang maka usahanya akan diberikan kepada UMKM atau PD Pasar Jaya. Sementara untuk menangani permasalahan tempat tinggal, Gubernur Basuki Tjahaja Purnama menawarkan rumah susun bagi masyarakat dengan KTP DKI Jakarta, sedangkan yang berasal dari luar DKI Jakarta akan dibiayai untuk kembali ke kampungnya. Selain dari pihak masyarakat lokal, elemen lain yang mengkritik lokalisasi Kalijodo adalah media massa yang menilai bahwa proses penertiban terlalu tergesagesa tanpa dilakukannya sosialisasi terhadap warga setempat (Friana, 2017). Komisi Nasional Hak Asasi Manusia (Komnas HAM) juga mendapatkan berbagai aduan dari warga Kalijodo yang merasa bahwa haknya tidak terpenuhi. Permasalahan yang muncul meliputi alokasi rumah tinggal dimana dari sebanyak 6.027 kepala keluarga baru 200 KK yang sudah mengisi Rusun Manrunda sedangkan sisanya terpaksa menyewa rumah kontrak atau tinggal di kolong jembatan. Permasalahan lainnya meliputi penggusuran PAUD Seruni Indah yang tercatat memiliki siswa sebanyak 135 anak. PAUD yang disediakan secara swadaya oleh masyarakat Kalijodo tersebut tidak diganti oleh Pemprov DKI. Warga Kalijodo juga belum mendapatkan kompensasi listrik dan air yang dijanjikan oleh Pemprov DKI sebesar 3 juta rupiah per-KK. Aduan yang didapat oleh Komnas HAM juga meliputi permasalahan mata pencaharian dimana terdapat pabrik bihun dan pabrik besi baut yang sudah berdiri selama ratusan tahun yang juga ikut tergusur (Tarigan, 2016).

Meskipun terdapat pihak yang tidak setuju dengan kebijakan tersebut, tidak sedikit pula yang mendukung penertiban kawasan Kalijodo. Dukungan yang diungkapkan oleh Ketua DPRD DKI Jakarta, Prasetyo Edi Marsudi, yang mengatakan bahwa lahan Kalijodo merupakan jalur hijau dan sudah seharusnya kawasan tersebut dikembalikan ke fungsi awalnya (Jordan, 2016). Kepala BPN Ferry Mursyidan juga menilai bahwa tindakan yang dilakukan oleh Pemprov DKI sudah tepat karena kawasan Kalijodo merupakan tanah negara yang berstatus ruang terbuka hijau bukan tempat pemukiman warga. Beliau juga mendukung segala bentuk bantuan sosial yang ditawarkan oleh Pemprov DKI Jakarta (Retaduari, 2016). Kebijakan ini juga mendapat dukungan penuh dari aparat pemerintah seperti TNI dan POLRI yang ikut serta mengawal proses penertiban kawasan Kalijodo.

Kebijakan penertiban kawasan Kalijodo erat kaitannya dengan konsep etika pengambilan keputusan publik atau etika institusi dan individu dalam sektor publik yang mencakup pendekatan etika konsekuensialis, pendekatan etika deantologis, dan pendekatan etika kebajikan dalam (Lynch, Lynch, \& Cruise, 2007; Segers \& Sullivan, 2006). Kebijakan Pemerintah Provinsi DKI Jakarta yang diputuskan oleh para pemangku kepentingan mulai dari gubernur hingga aparatur di bawahnya untuk melakukan penataan ini dapat dianalisis melalui tiga pendekatan tersebut. Berdasarkan latar belakang yang telah dijabarkan sebelumnya, penulis tertarik untuk menganalisis penerapan etika pengambilan keputusan publik dalam kebijakan penertiban kawasan Kalijodo oleh Pemerintah Provinsi DKI 
Jakarta. Adapun rumusan masalah yang dibuat adalah bagaimana penerapan etika pengambilan keputusan publik dalam kebijakan penertiban kawasan Kalijodo tahun 2016?

\section{TINJAUAN PUSTAKA}

Etika pengambilan keputusan dibagi ke dalam tiga tipe yaitu pendekatan konsekuensialis (consequentialist), pendekatan deantologis atau kantianisme (deontological atau kantian), dan etika kebajikan (virtue ethics) (Segers \& Sullivan, 2006). Teori ini juga disebutkan dalam (Lynch et al., 2007) yang digunakan untuk menganalisis etika institusi dan individu dalam sektor publik.

Pendekatan konsekuensialis berfokus pada konsekuensi dari suatu kebijakan, di mana kebijakan yang benar adalah kebijakan yang memiliki konsekuensi atau akibat yang lebih baik dari alternatif kebijakan lainnya. Konsep ini menekankan pada hasil atau akibat baik (best outcome) dalam mengevaluasi tindakan manusia (Pettit, 1997; Segers \& Sullivan, 2006). Best outcome yang dimaksud adalah meningkatkan sebanyak mungkin kesenangan, kebahagiaan, atau kepuasan bagi sebanyak mungkin orang (Christensen \& Lægreid, 2011). Pendekatan konsekuensialis adalah perkembangan dari buah pikiran Plato, Aristoteles, Cicero, yang menekankan pada manusia sebagai anggota dari komunitas yang berbagi tujuan bersama. Oleh sebab itu kebijakan sosial, sistem, sosial, institusi, dan lingkungan harus bermanfaat bagi setiap orang (Velasquez, Andre, Shanks, \& Meyer, 1996). Dalam implementasinya, pendekatan ini mendapat kritikan yaitu karena: (1) mengorbankan kepentingan segelintir orang demi tercapainya kepentingan banyak orang; (2) pengambil kebijakan tidak dapat memperkirakan seluruh konsekuensi yang mungkin terjadi dari suatu kebijakan tertentu; (3) menyangkut perhitungan/kalkulasi dari konsekuensi itu sendiri, sebab timbul pertanyaan mengenai kepentingan siapa yang harus diperhitungkan, bagaimana seharusnya biaya dan manfaat diukur, dan haruskah intensitas preferensi diukur (Segers \& Sullivan, 2006). Sementara itu menurut (Christensen \& Lægreid, 2011), permasalahan utama dari teori ini adalah betapa mudahnya menilai konsekuensi dari keputusan secara rasional. Perspektif 'economic man' mudah saja menentukannya, tetapi sebagai 'administrative man' memiliki adanya keterbatasan dalam perhatian dan kapasitas (Simon, 1957). Pendekatan konsekuensial adalah pendekatan yang digunakan sebagian besar pejabat publik.

Pendekatan deantologis atau kantianisme menekankan pada benar dan salah, ada kewajiban moral yang harus dilakukan selain dari pertimbangan konsekuensi (Lynch et al., 2007; Segers \& Sullivan, 2006). Pendekatan ini didasari oleh pemikiran Imannuel Kant. Kewajiban moral manusia ditentukan oleh lingkungan sosial di mana seseorang itu berada atau peran dan tanggung jawab dalam masyarakat yang menyertainya (Bradley, 1876). Contohnya menjadi orang tua, anak, tetangga, atau menjalankan profesi tertentu seperti dokter, pengacara, pejabat politik, dan lainnya, setiap orang memiliki pekerjaan yang harus dilakukan dan kewajiban moral untuk melakukannya dengan baik. Menurut John Rawls, paham ini berfokus pada manusia memperlakukan orang lain sama seperti dirinya ingin diperlakukan. Manusia memiliki martabat berdasarkan kehendak bebasnya dan memiliki hak moral dasar untuk membuat pilihan tersebut dihormati (Velasquez et al., 1996). Tindakan atau kebijakan yang benar dimaknai dengan individu yang bebas, setara, dan rasional. Contoh dari pendekatan deantologis adalah teori hak asasi manusia di mana menghormati hak adalah tanda menghormati orang sebagai tujuan hidup. (Segers \& Sullivan, 2006). Terdapat satu kritik mendasar mengenai teori ini yakni prinsip ini terlalu kaku untuk menjadi pedoman etis, sebab sering dibutuhkan adanya diskresi. Potensi masalahnya lainnya adalah adanya lebih dari satu prinsip yang dapat terlibat, memungkinkan adanya inkonsistensi yang mengarah pada trade off (Christensen \& Lægreid, 2011).

Pendekatan etika kebajikan berfokus pada sumber-sumber moralitas dalam kehidupan dan karakter batin ((Baron, Pettit, \& Slote, 2001; Lynch et al., 2007)). Etika ini mempertanyakan siapa kita dan kita harus menjadi orang yang seperti apa, hal ini berkaitan dengan potensi diri. ((Pence, 1993; Segers \& Sullivan, 2006)). Sumber teori ini berasal dari Aristoteles di mana ada cita-cita yang harus 
diperjuangkan karena memberikan perkembangan terhadap kemanusian. Pejabat publik dalam memutuskan tindakan atau kebijakan dalam situasi tertentu memanfaatkan pendekatan etika ini, oleh sebab itu institusi publik atau anggotanya harus menumbuhkan sifat-sifat karakter yang berbudi luhur dan melakukannya dalam perilaku sehari-hari (Deverette, 2002; Lynch et al., 2007). Dalam pengambilan keputusan yang melibatkan dilema moral, apa yang benar dan salah adalah bagian dari persamaan. Contoh dari tindakan yang dapat dilakukan dan dikembangkan adalah kejujuran, keberanian, belas kasih, kedermawanan, kesetiaan, integritas, keadilan, dan kebijaksanaan (Segers \& Sullivan, 2006). Etika kebajikan adalah bagian yang tidak terpisahkan dari kompetensi manajemen (Macaulay \& Lawton, 2006). Kritik terhadap teori ini yakni: (1) mengambil landasan moral yang terlalu tinggi dengan mengasumsikan setiap manusia adalah pribadi yang berbudi luhur; (2) tidak adanya aturan yang jelas mengenai pengambil kebijakan untuk membuat keputusan berdasarkan moral. (Lynch et al., 2007).

\section{Metode Penelitian}

Pendekatan dalam penulisan ini dikategorikan sebagai pendekatan deskriptif kualitatif. Penulis berbekal teori, pemahaman, dan data yang ada sehingga mampu menganalisis dan menjelaskan fenomena yang terjadi (Neuman, 2014) dalam hal ini yaitu melakukan analisis penerapan etika pengambilan keputusan dalam kebijakan penertiban kawasan Kalijodo tahun 2016. Objek penulisan makalah ini adalah Pemerintah Provinsi DKI Jakarta dan masyarakat Kalijodo. Teknik pengumpulan data yang digunakan dalam penulisan makalah ini adalah studi kepustakaan yang berarti penulisan makalah ini menggunakan literaturliteratur ilmiah seperti buku dan jurnal. Sumber data penulisan makalah ini menggunakan data sekunder, sehingga penulis tidak memperoleh secara langsung. Data sekunder yang digunakan adalah dokumen dan publikasi Pemerintah Provinsi DKI Jakarta, sumber elektronik, dan koran daring yang membahas mengenai kebijakan penertiban kawasan Kalijodo tahun 2016.

\section{Hasil dan Pembahasan}

Penggusuran yang dilakukan Pemprov DKI Jakarta pada kawasan Kalijodo bukanlah tanpa sebab. Kalijodo diproyeksikan oleh Pemprov DKI Jakarta menjadi Ruang Terbuka Hijau (RTH) serta Ruang Publik Terpadu Ramah Anak (RPTRA). Hal ini menjadi perhatian Pemprov DKI Jakarta karena minimnya ruang terbuka hijau yang ada di Jakarta. Dari luas kota yang mencapai $661.5 \mathrm{~km}^{2}$, ketersediaan ruang terbuka hijau di Jakarta masih dirasa sangat kurang dan masih jauh dari syarat yang ada dalam UU No. 26 Tahun 2007 tentang Penataan Ruang. Menurut data Dinas Pertamanan dan Pemakaman DKI Jakarta, luas Ruang Terbuka Hijau di Jakarta hanya sebesar 9.9\% dari total kebutuhan yang mencapai $30 \%$ dari luas suatu kota (Jakarta Smart City, 2016). Dengan kebutuhan Ruang Terbuka Hijau yang tinggi tersebut, Pemprov DKI Jakarta berusaha melakukan penataan kota dengan melakukan penggusuran kawasan-kawasan kumuh yang ada di Jakarta. Salah satunya adalah kawasan Kalijodo yang memang diketahui sebagai kawasan perkampungan kumuh di daerah Jakarta Utara. Dengan adanya penggusuran tersebut, total seluas 3,4 hektar lahan beralih fungsinya menjadi Ruang Terbuka Hijau (BCI Asia, 2017). Selain itu, Kalijodo sendiri dikenal sebagai kawasan premanisme, prostitusi, dan perjudian yang ada di DKI Jakarta. Prostitusi ini dilakukan di rumahrumah semi permanen yang kondisinya kumuh. Dengan kondisi seperti ini, banyak dari pekerja seks komersial di kawasan Kalijodo yang akhirnya menderita Human Immunodeficiency Virus (HIV). Dilihat pula dari data Kementerian Kesehatan bahwasannya Provinsi DKI Jakarta merupakan provinsi di Indonesia dengan jumlah penderita HIV tertinggi dengan jumlah 55.099 penderita (Kementerian Kesehatan, 2016). Melalui kondisi tersebut, menjadi alasan pendukung bagi pemerintah untuk mengusulkan penggusuran lahan di Kalijodo.

Melihat pada pendekatan konsekuensialis, penggusuran kawasan Kalijodo oleh Pemprov DKI Jakarta dirasa adalah pengambilan keputusan yang tepat. Hal ini melihat pada dampak yang dihasilkan dari kebijakan penggusuran kawasan Kalijodo yang memberikan kebermanfaatan bagi lebih banyak 
orang, walaupun tetap dalam praktiknya mengorbankan kepentingan segelintir orang. Setelah penggusuran tersebut, kawasan Kalijodo yang identik dengan kehidupan malam berubah statusnya menjadi salah satu tempat rekreasi yang ada di Jakarta. Dengan menggandeng perusahaan swasta yaitu PT Sinarmas Land, Pemprov DKI Jakarta membangun berbagai fasilitas yang terdapat pada Ruang Publik Terpadu Ramah Anak (RPTRA) seperti arena skateboard, ruang perpustakaan, aula, ruang menyusui, area taman bermain, hingga area pedagang makanan. Dengan berbagai fasilitas yang disediakan ini, Kalijodo yang dahulunya kawasan kumuh berubah menjadi Ruang Terbuka Hijau. Selain sebagai daerah penghijauan dan resapan air, dengan adanya RTH ini juga memberikan wadah bagi masyarakat sekitar Kalijodo untuk dapat bersosialisasi dan memperkuat jalinan dalam masyarakat. Kemudian dengan statusnya sebagai Ruang Publik Terpadu Ramah Anak, di tempat ini pula dapat dijadikan sebagai sarana pendidikan serta pengembangan anak-anak sekitar Kalijodo. Sebab saat ini di Jakarta jumlah ruang-ruang publik yang ramah anak masih dirasa minim, sebab sebagai sebuah perkotaaan, Jakarta seharusnya mampu menyediakan ruang-ruang publik bagi anak-anak untuk dapat bermain (Friana, 2017). Makin gencarnya pembangunan terhadap gedung-gedung bertingkat, menyebabkan anak-anak harus kehilangan tempat untuk dapat bermain dan mengembangkan potensinya. Walaupun dampak yang dihasilkan baik, tetapi penggusuran kawasan Kalijodo juga menimbulkan masalah baru yang tidak terencanakan sebelumnya. Para warga Kalijodo yang direlokasi ke berbagai Rumah Susun (Rusun) di Jakarta, mengeluhkan berbagai persoalan. Para mantan warga Kalijodo merasa kehilangan mata pencaharian mereka, sebab banyak dari warga Kalijodo yang menggantungkan hidupnya disana. Selain itu mereka juga menuntut kompensasi dari Pemerintah Provinsi DKI Jakarta terkait naiknya biaya kebutuhan hidup mereka selama tinggal di Rumah Susun. (Tarigan, 2016; Widhana, 2016)

Sementara itu dari sudut pandang deantologis, dapat dilihat bahwa kebijakan penggusuran yang dilakukan Pemprov DKI Jakarta bukanlah tanpa payung hukum. Pemerintah menggunakan dasar hukum Peraturan Daerah Nomor 8 Tahun 2007 tentang ketertiban umum (Sari, 2017). Walaupun telah memiliki payung hukum, penggusuran yang dilakukan oleh Pemerintah Provinsi DKI Jakarta mendapat pertentangan dari berbagai pihak, salah satunya adalah Lembaga Bantuan Hukum. LBH berpendapat bahwa penggusuran yang dilakukan Pemprov DKI Jakarta yang berpedoman Peraturan Daerah Nomor 8 Tahun 2007 cacat hukum (Sari, 2017). Dengan peraturan tersebut, Pemprov DKI Jakarta seolah-oleh memiliki kewenangan lebih untuk dapat melakukan penertiban umum, salah satunya adalah tindakan penggusuran. Dari perspektif deontologis, tindakan yang diambil oleh Pemerintah Provinsi DKI Jakarta dapat dibenarkan. Gubernur Basuki Thahaja Purnama jelas memiliki pertimbangan khusus dalam melakukan suatu tindakan yang akan diambil. Seperti pada tindakan penggusuran yang ia lakukan, dia berpendapat bahwa penggusuran yang dilakukan untuk mengurangi potensi bencana banjir yang terdapat di Jakarta serta mengembalikan fungsi lahan sesuai peruntukkannya (Kumparan, 2017). Pemprov DKI Jakarta dalam kasus ini memiliki wewenang yang diatur dalam Pasal 1 angka 23 UU No. 23 Tahun 2014. Adapun urusan wajib yang menjadi tanggung jawab pemerintah daerah adalah urusan wajib yang berkaitan dengan pelayanan dasar, meliputi: pendidikan, kesehatan, pekerjaan umum dan penataan ruang, perumahan dan kawasan permukiman, ketertiban umum serta perlindungan masyarakat dan sosial (Pradityo, 2017). Jika mengacu pada Undang-Undang ini, tindakan yang diambil Pemerintah Provinsi DKI Jakarta dalam menggusur Kalijodo dapat dikatakan sebuah upaya untuk melakukan penataan ruang. Dengan begitu, Pemprov DKI Jakarta hanya menjalankan peran, fungsi, dan tanggung jawabnya semaksimal mungkin.

Terakhir, apabila ditinjau dari pendekatan etika kebajikan maka tindakan Pemprov DKI Jakarta tidak sepenuhnya dianggap sebagai suatu kebenaran. Penggusuran yang dilakukan kepada masyarakat Kalijodo, dalam beberapa kasus tidak berjalan sesuai dengan mekasnisme yang seharusnya. Banyak warga yang memiliki lahan 
ataupun bangunan yang dilengkapi oleh Sertifikasi Garap, namun tidak mendapatkan proses ganti rugi oleh Pemprov DKI Jakarta. Menurut salah satu tokoh di Kalijodo, Abdul Azis atau kerap disapa Daeng Azis mengaku rutin membayar Pajak Bumi dan Bangunan Pedesaan Perkotaan (PBB-P2). Sehingga beberapa warga Kalijodo merasa memiliki hak atas lahan dan bangunan tersebut. Walaupun Pemerintah Provinsi berdalih bahwa Daeng Azis menyalahi peraturan dan dapat dipidana karena dianggap membeli dan menguasai tanah negara (Alexander, 2016). Dengan polemik ini, harusnya Pemerintah Provinsi DKI Jakarta mampu menyelesaikan kasus ini. Suatu hal yang patut diapresiasi adalah ketika kawasan Kalijodo ini ditertibkan pada 29 Februari 2016, tidak ada perlawanan dari masyarakat sama sekali. Penertiban berlangsung lancar dan ratusan aparat yang dikerahkan juga tidak melakukan tindakan anarkis (BBC Indonesia, 2016). Menurut pendekatan etika kebajikan, tindakan yang diambil Pemerintah Provinsi DKI Jakarta seharusnya tetap mengedepankan nilai-nilai luhur dalam hal ini termasuk pula belas kasih. Walaupun kawasan Kalijodo yang sebelumnya dijadikan tempat dan pusat kegiatan lokalisasi yang tentunya dapat dikatakan sebagai pelanggaran hukum, namun Pemprov DKI Jakarta harus dapat memenuhi hak masyarakat dan menjunjung tinggi nilai-nilai kemanusiaan. Walaupun menurut Kementerian Agraria dan Tata Ruang, Ferry Mursyidan Baldan tindakan penggusuran yang dilakukan oleh Pemerintah Provinsi DKI Jakarta tidak memerlukan adanya proses ganti rugi. Ia berpendapat bahwa Kalijodo merupakan kawasan yang statusnya adalah tanah negara yang peruntukannya bagi ruang terbuka hijau (Andinni, 2016). Bentuk tanggung jawab Pemerintah Provinsi DKI Jakarta kepada korban Kalijodo selain memberikan rumah susun kepada korban yang terdampak, para pekerja seks komersial juga diberikan pelatihan profesi oleh Dinas Tenaga Kerja Provinsi DKI Jakarta (Sasongko, 2016). Hal ini dimaksudkan agar para mantan pekerja seks komersial ini tidak kembali ke profesi sebelumnya dan mampu memberdayakan masyarakat di sekitar Kalijodo yang terdampak dengan penggusuran tersebut.

\section{Kesimpulan}

Berdasarkan analisis yang telah dilakukan terhadap penerapan etika pengambilan keputusan publik terhadap kebijakan penertiban kawasan Kalijodo oleh Pemprov DKI Jakarta meliputi pendekatan etika konsekuensialis, etika deantologis, dan etika kebajikan, maka dapat ditarik suatu kesimpulan bahwa dalam pengambilan kebijakan tersebut sudah diterapkan kombinasi dari ketiga pendekatan tersebut. Etika konsekuensialis menjadi pendekat yang paling kuat digunakan sebab menimbang best outcome yang menghadirkan manfaat bagi lebih banyak orang walau di sisi lain mendatangkan kerugian bagi sebagian pihak. Diikuti dengan etika deantologis, di mana pemerintah memiliki kewajiban mengeluarkan keputusan dalam perannya sebagai aparatur negara. Etika kebajikan juga diimplementasikan walau pengaruhnya tidak signifikan.

Saran yang dapat penulis berikan mengenai pengambilan keputusan publik di dalam kasus penertiban kawasan Kalijodo ini adalah bahwa Pemprov DKI Jakarta harus menyadari setiap keputusan yang dibuat tidak dapat menyenangkan setiap aktor kepentingan yang ada. Dalam pengambilan keputusan publik ini patut disadari bahwa setiap perspektif etika pengambilan keputusan yang ada memiliki kelemahannya masing-masing, sehingga dalam pengambilan keputusan publik yang baik diperlukan adanya 'segitiga etika' agar terjadi keseimbangan antar pendekatan etika tersebut. Terkait dalam pengambilan keputusan penertiban kawasan ataupun kebijakan-kebijakan lainnya yang menyangkut hajat hidup orang banyak, Pemprov DKI Jakarta seharusnya tidak hanya mengedepankan perspektif konsekuensialis dalam hal ini 'economic man', namun juga mengaplikasikan 'administrative man', sehingga tidak hanya kalkulasi biaya dan untung rugi, namun juga meliputi hubungan sosial, perilaku manusia, budaya, dan hal-hal luhur lainnya yang berkaitan dengan mengedepankan etika kebajikan dengan menjunjung tinggi hak-hak masyarakat. 


\section{Daftar Pustaka}

Alexander, H. B. (2016). Pemprov DKI Jakarta Harus Bayar Ganti Rugi Korban Kalijodo.

Retrieved from https://properti.kompas.com/read/2016/02/16/1 20000721/Pemprov.DKI.Jakarta.Harus.Bayar. Ganti.Rugi.Korban.Kalijodo.?page=all

Andinni, A. R. (2016). Menteri Agraria: Tak Perlu Ganti Rugi Penggusuran Kalijodo. Retrieved from https://www.cnnindonesia.com/nasional/20160 301185231-20-114679/menteri-agraria-takperlu-ganti-rugi-penggusuran-kalijodo

Baron, M., Pettit, P., \& Slote, M. (2001). Three methods of ethics.

BBC Indonesia. (2016). Pembongkaran Kalijodo lancar tanpa perlawanan. Retrieved from https://www.bbc.com/indonesia/berita_indones ia/2016/02/160229_indonesia_kalijodo_update

BCI Asia. (2017). Projects : RTH dan RPTRA Kalijodo. Retrieved from http://www.constructionplusasia.com/id/rthdan-rptra-kalijodo/\%0A

BPS Provinsi DKI Jakarta. (2017). Jumlah Penduduk dan Rasio Jenis Kelamin. Retrieved from

https://jakarta.bps.go.id/statictable/2017/01/30/ 137/jumlah-penduduk-dan-rasio-jenis-kelaminmenurut-kabupatenkota-di-provinsi-dkijakarta-2015.html

Bradley, F. H. (1876). My station and its duties. Ethical Studies, 164-165.

Christensen, T., \& Lægreid, P. (2011). Ethics and administrative reforms: A study of ethical guidelines in the central civil service. Public Management Review, 13(3), 459-477.

Deverette, R. J. (2002). Introduction to Virtue Ethics. Washington, DC: Georgetown UP.

Eko, E. (2019). Problematika Kemacetan Jakarta. Retrieved from https://www.kompasiana.com/edwardiyonoeko prasojo/5d110632097f365f25427c63/problema tika-kemacetan-jakarta

Friana, H. (2017). Pengamat Nilai Jumlah Ruang Terbuka Hijau di Jakarta Stagnan. Retrieved from https://tirto.id/pengamat-nilai-jumlahruang-terbuka-hijau-di-jakarta-stagnan-co4Q jakarta.go.id. (2008). GEOGRAFIS JAKARTA. Jakarta Smart City. (2016). Jakarta akan Memenuhi Kebutuhan Ruang Terbuka Hijau. Retrieved from https://smartcity.jakarta.go.id/blog/114/jakarta- akan-memenuhi-kebutuhan-ruang-terbukahijau\%0A

Jordan, R. (2016). Dukung Penertiban Kalijodo, Ketua DPRD DKI: Pemerintah Tak Boleh Kalah! Retrieved from https://news.detik.com/berita/3141779/dukungpenertiban-kalijodo-ketua-dprd-dkipemerintah-tak-boleh-kalah

Kementerian Kesehatan. (2016). Hari AIDS Sedunia, Momen STOP Penularan HIV: Saya Berani, Saya Sehat! Retrieved from https://www.depkes.go.id/article/view/181203 00001/hari-aids-sedunia-momen-stoppenularan-hiv-saya-berani-saya-sehat-.html Kumparan. (2017). Ahok Ungkap Alasan Tetap Lakukan Penggusuran. Retrieved from https://kumparan.com/kumparannews/ahokungkap-alasan-tetap-lakukan-penggusuran

Lynch, T. D., Lynch, C. E., \& Cruise, P. L. (2007). Global Ethics in the 21st Century: An Alternative Approach. PUBLIC ADMINISTRATION AND PUBLIC POLICYNEW YORK-, 129, 903.

Macaulay, M., \& Lawton, A. (2006). From virtue to competence: Changing the principles of public service. Public Administration Review, 66(5), 702-710.

Neuman, W. L. (2014). Social Research Methods: Qualitative and Quantitative

Approaches 7th Edition. Essex: Pearson Education Limited.

Pence, G. (1993). Virtue theory. A Companion to Ethics, 249-258.

Pettit, P. (1997). The consequentialist perspective.

Pradityo, R. Y. (2017). Menyibak Peran dan Fungsi Pemerintahan Provinsi DKI Jakarta. Retrieved from

https://www.netralnews.com/news/opini/read/1 08737/menyibak-peran-dan-fungsipemerintahan-provinsi-dki-jakarta-

Pratomo, H. (2012). DKI Jakarta, penyumbang terbesar ekonomi nasional. Retrieved from https://www.merdeka.com/uang/dki-jakartapenyumbang-terbesar-ekonomi-nasional.html

Retaduari, E. A. (2016). Kepala BPN: Kalijodo Tanah Negara, Penertiban Pemprov DKI Sudah Benar.

Rizal. (2016). Sejarah Berdirinya Lokalisasi Kalijodo yang Selama Ini Selalu Tabu untuk Dibicarakan. Retrieved from https://www.idntimes.com/news/indonesia/riza 1/sejarah-berdirinya-lokalisasi-kalijodo-sejakera-kolonial-belanda-hingga-sebesarsekarang/full 
Sari, N. (2017). LBH Sayangkan Perda Ketertiban Umum jadi Dasar Hukum Penggusuran di Jakarta. Retrieved from https://megapolitan.kompas.com/read/2017/04/ 13/16291211/lbh.sayangkan.perda.ketertiban.u mum.jadi.dasar.hukum.penggusuran.di.jakarta $\% 0 \mathrm{~A}$

Sasongko, J. P. (2016). Pemprov DKI Siapkan Pelatihan Alih Profesi untuk PSK Kalijodo. Retrieved from https://www.cnnindonesia.com/nasional/20160 215152728-20-111033/pemprov-dki-siapkanpelatihan-alih-profesi-untuk-psk-kalijodo

Segers, M., \& Sullivan, E. (2006). Ethical Issues and Public Policy. 309-327. https://doi.org/10.1201/9781420017007.ch21

Simon, H. A. (1957). Administrative behaviour; a study of decisionmaking process in administrative organization, New York, 1957. New York: MacMillan.

Tambun, L. (2016). Selama Menjadi Gubernur DKI, Ahok Telah Lakukan 12 Penggusuran.

Retrieved from https://www.beritasatu.com/megapolitan/3892 84/selama-menjadi-gubernur-dki-ahok-telahlakukan-12-penggusuran

Tarigan, K. (2016). Untuk Pak Ahok: Komnas HAM Ungkap Derita Warga Setelah Kalijodo Digusur.

Velasquez, M., Andre, C., Shanks, T., \& Meyer, M. J. (1996). Thinking ethically: A framework for moral decision making. Issues in Ethics, 7(1).

Widhana, D. H. (2016). Balada Korban Penggusuran yang Tinggal di Rusun. Retrieved from https://tirto.id/balada-korbanpenggusuran-yang-tinggal-di-rusun-ccoQ

Wijaya, P. (2013). Analisis Pembangunan RTH

Publik di Jakarta Timur (Universitas Indonesia). Retrieved from http://lib.ui.ac.id/naskahringkas/201604/S46986-Putra Wijaya 